\title{
PENGARUH ROLE MODEL GURU TERHADAP KESADARAN PERILAKU HIDUP BERSIH SEHAT SISWA
}

\author{
${ }^{1}$ STIKES Widyagama Husada \\ ${ }^{2}$ STIKES Widyagama Husada \\ Corresponding author: \\ Mizam Ari Kurniyanti \\ STIKES Widyagama Husada \\ Email:_mizam_ari@widyagamahusada.ac.id
}

Mizam Ari Kurniyanti ${ }^{1 *}$, Clara Cassandra Resubun ${ }^{2}$

\section{Article Info:}

Dikirim: 28 Agustus 2020

Ditinjau: 06 Oktober 2020

Diterima: 06 November 2020

DOI:

https://doi.org/10.33475/jikmh

\begin{abstract}
Clean and healthy education behaviors to kindergarden child important because kindergarden child is the age of vulnerable to health problems. Teachers as role model is necessary to give a good example to students about PHBS.Design research is analytic observation, with cross sectional approach. Data Analysis to be used the wilcoxon for analyze influence role model (knowledge and the role of ) teachers on raising awareness behaviors fresh healthy kindergarten students. Research results obtained the significance of knowledge and role of teachers as rolemodel is 0.189 which means there is no significant difference between knowledge and teachers before and after guidance on the importance of phbs on the kids. The results of the analysis between behavior phbs students before and after development in the class of the teacher, and the results of significance is 0.00 which would mean there are significant influence between behavior phbs students before and after guidance that given for the teacher.The results of the analysis of the influence of rolemodel ( knowledge and a role on raising awareness of the teacher who was healthy patterns of living students and the results of significance as much as 0.898 which means it the weight is irrelevant rolemodel on raising awareness of the teacher. It can be concluded that when knowledge and role of teachers will attitude PHBS students was also good will and when knowledge and role of teachers decreased so PHBS attitude students to understand the decreased.
\end{abstract}

Keywords: Teacher; Role Model; Attitude, PHBS

\begin{abstract}
Abstrak
Pendidikan perilaku hidup bersih dan sehat terhadap anak taman kanak-kanak perlu dilakukan mengingat anak taman kanak-kanak merupakan kelompok umur yang rawan terhadap masalah kesehatan. Peran guru sebagai Role Model diperlukan untuk memberikan contoh yang baik kepada siswa tentang PHBS. Desain penelitian ini adalah analitik observasi, dengan pendekatan cross sectional. Analisis data yang akan digunakan menggunakan uji Wilcoxon untuk menganalisa adakah pengaruh Role Model (pengetahuan dan peran) guru wali kelas Terhadap Peningkatan Kesadaran Perilaku Hidup Bersih Sehat Siswa TK Syuhada. Hasil penelitian didapatkan hasil signifikansi pengetahuan dan peran guru sebagai rolemodel adalah 0.189 yang berarti tidak terdapat perbedaan yang signifikan antara Pengetahuan dan guru sebelum dan sesudah pembinaan tentang pentingnya PHBS pada siswa. Hasil analisis antara perilaku PHBS siswa sebelum dan sesudah pembinaan pada guru wali kelas, didapatkan hasil signifikansi adalah 0.00 yang berarti ada pengaruh yang signifikan antara perilaku PHBS siswa sebelum dan sesudah pembinaan yang diberikan pada guru wali kelas. Hasil analisis tentang pengaruh Rolemodel(pengetahuan dan peran) guru wali kelas terhadap peningkatan kesadaran perilaku hidup sehat siswa didapatkan hasil signifikansi sebesar 0.898 yang berarti tidak ada pengaruh Rolemodel Guru wali kelas terhadap peningkatan kesadaran Perilaku Hidup Bersih Sehat Siswa TK Syuhada. Disimpulkan bahwa apabila pengetahuan dan peran guru baik maka sikap PHBS siswa juga akan baik, dan apabila pengetahuan dan peran guru jelek maka sikap PHBS siswa juga akan jelek.
\end{abstract}

Kata Kunci: Guru; Role Mode; Perilaku; PHBS 


\section{PENDAHULUAN}

PHBS pada siswa taman kanak-kanak sangat penting mengingat anak usia taman kanak-kanak merupakan kelompok umur yang rawan terhadap masalah kesehatan, sehingga PHBS diterapkan di sekolah. PHBS Sekolah adalah usaha untuk memberdayakan siswa, guru dan masyarakat yang ada di lingkungan sekolah agar dapat menerapkan perilaku bersih dan sehat yang bertujuan ungtuk mewujudkan sekolah sehat

Dalam penerapan PHBS sangat diperlukan peran serta guru sebagai pengajar dalam memberikan pengetahuan tentang perilaku bersih dan sehat kepada siswanya.

Pelaksanaan PHBS disekolah ini juga memerlukan kerjasama antara guru dan orang tua siswa, dimana guru diharapkan dapat menjadi role model atau panutan siswa dalam penerapan PHBS di sekolahannya (Rink \& Hall, 2013).

\section{METODE}

Desain penelitian ini adalah analitik observasi, dengan pendekatan cross sectional. Analisis data yang akan digunakan menggunakan uji $\mathrm{T}$ berpasangan/Wilcoxon dimana uji tersebut dilakukan untuk menentukan terdapat perbedaan rerata yang bermakna antara 2 kelompok yaitu PHBS sebelum pembinaan dan Sesudah pembinaan pada guru TK Syuhada tentang pentingnya PHBS pada siswa, perilaku PHBS siswa TK Syuhada sebelum dan sesudah pembinaan guru, sedangkan untuk menganalisa adakah pengaruh Role Model (pengetahuan dan peran) guru wali kelas Terhadap Peningkatan Kesadaran Perilaku Hidup Bersih Sehat Siswa TK Syuhada menggunakan uji Wilcoxon.

\section{HASIL DAN PEMBAHASAN}

\section{Pengetahuan Guru sebagai Rolemodel sebelum dan sesudah pembinaan PHBS}

Berdasarkan hasil penelitian didapatkan data perbandingan pengetahuan dan peran guru sebagai rolemodel sebelum dan sesudah pembinaan PHBS yaitu rerata sebelum pembinaan adalah sebesar 29 sedangkan setelah pembinaan didapatkan hasil reratanya sebesar 30 yang berarti ada peningkatan pengetahuan tetapi tidak terlalu signifikan dan hal ini juga dibuktikan dari hasil analisis yaitu sebesar 0.189 yang berarti tidak terdapat perbedaan yang signifikan antara Pengetahuan dan guru Guru sebelum dan sesudah pembinaan tentang pentingnya PHBS pada siswa.

Dari hasil wawancara didapatkan data bahwa sebelumnya pernah ada penyuluhan yang dilakukan oleh mahasiswa instansi lain terkait mengenai PHBS tetapi tidak dijelaskan apa pentingnya guru untuk mengajarkan atau memberikan contoh PHBS tersebut pada siswa-siswinya. Dari hasil interview dengan salah satu guru wali kelas, didapatkan data bahwa mereka faham bahwa phbs sangat penting untuk diterapkan hanya saja tidak pernah mengajarkan kepada siswa-siswinya. Pada pembinaan yang diberikan oleh peneliti kepada guru tidak hanya ditekankan pada materi PHBS saja tetapi lebih ke arah pentingnya PHBS ini diterapkan oleh siswa-siswi disekolahnya, bagaimana peranan guru wali kelas sebagai rolemodel siswa siswinya dalam penerapan PHBS disekolahan.

Hal ini sesuai dengan pernyataan dari Notoatmojo(2010) yang menyatakan bahwa perubahan perilaku dengan pembinaan dan penyuluhan memerlukan waktu lama, akan tetapi perubahan yang dicapai bersifat langgeng apabila didasari oleh kesadaran mereka sendiri. 
Hal ini sejalan dengan penelitian Solehati, Susilawati, Lukman dan Kosasih (2015) yang menyatakan bahwa Penkes erat kaitannya dalam meningkatkan pengetahuan guru tentang pentingnya PHBS, selain itu dengan adanya kesadaran diri tentang pentingnya PHBS maka akan memberikan motivasi kepada guru untuk memberikan contoh penerapan PHBS dengan harapan agar para siswa dapat mengikuti apa yang sudah dicontohkan

\section{Perilaku PHBS Siswa Sebelum dan Sesudah Pembinaan PHBS}

Berdasarkan hasil penelitian didapatkan data perbandingan pengetahuan PHBS siswa sebelum dan sesudah pembinaan PHBS guru yaitu Rerata sebelum dilakukan pembinaan yaitu sebesar 142, sedangkan Rerata sesudah pembinaan sebesar 150 yang berarti ada peningkatan dalam perilaku PHBS siswa setelah diadakan pembinaan baik pada guru dengan hasil signifikasi sebesar 0,000 yang berarti ada pengaruh yang signifikan antara perilaku PHBS siswa sebelum dan sesudah pembinaan yang diberikan pada guru wali kelas.

Dari hasil observasi yang dilakukan kepada siswa setelah pembinaan, diketahui bahwa guru wali kelas memberikan contoh pada siswa-siswanya bagaimana cara mencuci tangan yang benar setiap sebelum masuk kelas dan setelah kelas berakhir, dan hal itu ditiru oleh sebagian siswa-siswa yang ada di TK Syuhada, meskipun memang tahapan cuci tangan masih belum sempurna ditirukan oleh siswasiswanya.

Dari hasil Observasi peneliti terhadap Perilaku buang sampah dan kerapian diri juga terlihat ada peningkatan perilaku ketika setelah selesai pembinaan, yaitu dimulai dari guru wali kelas yang selalu ada didepan ruang kelas untuk memeriksa kerapian rambut, baju, jilbab atau kopyah yang dipakai oleh siswa-siswinya ketika berangkat kesekolah, adanya pemeriksaan kuku tangan dan kaki siswa-siswi setiap hari jumat disetiap minggunya, dan mulai terlihat adanya peningkatan perubahan perilaku pada minggu ke 3 dan 4 meskipun masih ada juga siswa-siswi yang kerapian dirinya masih kurang.

Hasil analisis didapatkan signifikansi sebesar 0,000 yang berarti ada peningkatan yang signifikan pada perilaku PHBS siswa sebelum dan sesudah pembinaan PHBS pada guru.

Hal ini sesuai dengan yang dikemukakan oleh Notoatmojo (2010) yang menyatakan bahwa Perilaku hidup bersih dan sehat adalah upaya untuk memberikan pengalaman belajar atau menciptakan suatu kondisi bagi perorangan, keluarga, kelompok dan masyarakat dengan membuka jalur komunikasi, memberikan informasi melalui pendekatan pimpinan (advocacy), bina suasana (social support) dan pemberdayaan masyarakat (empowerment). Seseorang dapat mengenali dan mengatasi masalahnya sendiri dan dapat menerapkan cara-cara hidup sehat dengan menjaga, memelihara dan meningkatkan kesehatannya

Guru merupakan role model atau panutan dari siswanya, sehingga apabila guru memiliki pengetahuan yang benar tentang PHBS maka informasi tersebut akan dapat tersampaikan pada siswanya (Dede, 2017)

Hal ini terlihat bahwa Peran guru sebagai rolemodel yang memberikan contoh terkait PHBS pada siswa berdampak positif pada peningkatan sikap siswa terhadap PHBS. Hal ini terbukti bahwa setelah diberikan pembinaan dan guru wali kelas memberikan contoh tentang cuci tangan, memotong kuku, membuang sampah ditempatnya, kerapian baju dan rambut, kebersihan kaos kaki terdapat peningkatan pada Perilaku PHBS Siswa yaitu terdapat 35 siswa yang sikap PHBSnya meningkat. 


\section{Pengaruh Role Model (pengetahuan dan peran)} guru wali kelas Terhadap Peningkatan Kesadaran Perilaku Hidup Bersih Sehat Siswa TK Syuhada

Berdasarkan hasil penelitian didapatkan signifikansi 0.898 yang berarti tidak ada pengaruh Rolemodel Guru wali kelas terhadap peningkatan kesadaran Perilaku Hidup Bersih Sehat Siswa TK Syuhada. Hal ini juga berarti bahwa apabila pengetahuan dan peran guru baik maka sikap PHBS siswa juga akan baik, dan apabila pengetahuan dan peran guru jelek maka sikap PHBS siswa juga akan jelek.

Hal ini sesuai dengan pernyataan dari Menteri Kesehatan Nila Moeloek yang menyatakan perilaku hidup sehat dimulai dari guru dulu yang berperilaku sehat, dan siswa juga akan mengikuti yang memiliki tujuan untuk mempromosikan hidup sehat. (Herman, 2015)

Menurut penelitian Gustina (2015), terbukti bahwa terdapat pengaruh antara sumber informasi dengan pengetahuan seseorang.

Peran guru adalah menyesuaikan sikap agar perilaku guru dapat menjadi teladan sehingga mendukung proses pembentukan kepribadian peserta didik. (Dede, 2017).

Penelitian yang dilakukan oleh Albert Bandura dan Frederick menyatakan Role Model dapat secara signifikan mendukung pembentukan kepribadian peserta didik khususnya penguatan terhadap kesesuaian tindakan peserta didik dalam mengamati dan meniru model (guru). Selain itu,

Guru harus bisa membangun kepercayaan akan dirinya pada peserta didik. Karena peserta didik lebih mudah meniru orang yang dipercayainya daripada yang tidak. Adapun dari pihak peserta didik dipahami bahwa peserta didik yang bermotivasi tinggi akan mudah meniru model untuk menguasai perilaku yang diinginkan. (Dede, 2017)
Dalam konteks pendidikan, siswa akan menjadikan guru sebagai Role model sehingga akan membentuk kepribadian siswa mendekati sang guru. Hasil pengamatan siswa akan ragam sikap guru dalam melakukan perilaku hidup bersih sehat akan di imitasi atau ditiru oleh siswanya ketika melakukan hal yang sama. (Dede, 2017).

\section{KESIMPULAN}

Terdapat pengaruh yang signifikan antara perilaku PHBS siswa sebelum dan sesudah pembinaan yang diberikan pada guru wali kelas. Hasil analisis tentang pengaruh Rolemodel(pengetahuan dan peran) guru wali kelas terhadap peningkatan kesadaran perilaku hidup sehat siswa tidak terdapat pengaruh Rolemodel Guru wali kelas terhadap peningkatan kesadaran Perilaku Hidup Bersih Sehat Siswa TK Syuhada. Dari hasil penelitian dapat disimpulkan bahwa apabila pengetahuan dan peran guru baik maka sikap PHBS siswa juga akan baik, dan apabila pengetahuan dan peran guru jelek maka sikap PHBS siswa juga akan jelek.

\section{UCAPAN TERIMA KASIH}

Ucapan terima kasih disampaikan kepada para Guru dan Siswa TK Syuhada Kota Malang yang telah berpartisipasi sebagai responden dalam penelitian ini. Ucapan terima kasih kepada STIKES Widyagama Husada yang telah memberikan dukungan moril dan materil melalui Skema Hibah Internal dalam proses penelitian ini.

\section{DAFTAR RUJUKAN}

Dede, R. H. (2017, Maret 30). Jejak Pendidikan Portal Pendidikan Indonesia. Retrieved 
Oktober 9, 2018, from Jejak Pendidikan Portal Pendidikan Indonesia: http://www.jejakpendidikan.com/2017/03/pera n-guru-sebagai-role-model.html

E, G., \& Djanah. (2015). Sumber informasi dan pengetahuan tentang menstrual hygiene pada remaja putri. Jurnal Kesmas , 147-152.

Herman. (2015, Februari 2). Guru Diharapkan Jadi Teladan Perilaku Hidup Bersih dan Sehat. Retrieved Oktober 10, 2018, from Guru Diharapkan Jadi Teladan Perilaku Hidup Bersih dan Sehat:

http://www.beritasatu.com/kesra/245683-gurudiharapkan-jadi-teladan-perilaku-hidup-bersihdan-sehat.html

Linda, Farit, R., \& Farzan, A. (2016). Strategi Pemberdayaan Guru Dalam Peningkatan Pengetahuan, Sikap Dan Tindakan Terhadap Perilaku Hidup Bersih Dan Sehat Pada Murid
Sdn 06 Poasia Kota Kendari. JIMKESMAS , 111.

Moore, C. M. (2012). The Role of School Environment in Teacher Dissatisfaction Among U.S. Public School Teachers. CLINICAL focus , 14-20.

Rink, J., \& Hall, T. (2013). The Role and Responsibilities of the Physical Education Teacher in the School Physical Activity Program. Humankinetics Journal , 20-23.

Solehati, T., Susilawati, S., Lukman, M. L., \& Kosasih, C. E. (2015). Pengaruh Edukasi Terhadap Pengetahuan Dan Skill Guru Serta Personal Hygiene Siswa Sd. KEMAS , 135-143. Strachan, H. (2011). Caring - The Concept, Behaviours, Influences and Impact. NMAHP Quality Council , 1-19.

Cite this article as: Kurniyanti, MA., dan Clara C.R. (2020). Pengaruh Role Model Guru Terhadap Kesadaran Perilaku Hidup Bersih Sehat Siswa. Jurnal Ilmiah Media Husada. 9(2), 100-104. https://doi.org/10.33475/jikmh. 